\title{
Better attitudes and mental health for our future
}

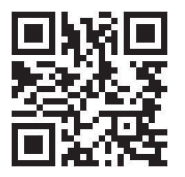

Two issues of the South African Journal of Psychiatry applaud a future in which South Africa pursues both better mental health and better attitudes towards psychiatric difficulties and illnesses. The first, a Special Issue of the $S A J P$, features the Treatment Guidelines of the South African Society of Psychiatrists, ${ }^{[1]}$ which is published by the SAJP without being subsidised by advertisements from the pharmaceutical industry. This is the first publication of its kind in South Africa, resulting from peer consultation and refinement by psychiatrists and carefully compiled and edited by Professors Soraya Seedat and Robin Emsley. It aims to cater to both the public and private sectors of psychiatric practice.

Our 'ordinary' issue of the SAJP, the third of 2013 (Vol. 19), has similar concerns to the Special Issue, i.e. advocating better mental health. But it is not 'ordinary' for at least two reasons: it contains the abstracts of the Biological Psychiatry Conference; and the papers published within collectively call for better attitudes towards, and understanding of mental health difficulties. Moosa and Jeenah ${ }^{[2]}$ consider the ethics of provider-initiated HIV counselling and testing among people with mental illness, working against the double stigmatisation attached to both mental illness and HIV status. Also working against stigmatisation, Vijayalakshmi et al. ${ }^{[3]}$ and Pretorius and Broodryk ${ }^{[4]}$ consider misconceptions about mental illness and traumatic brain injuries, respectively, held in educational settings. Both papers propose educational interventions that foster more accurate understanding of, and better attitudes towards mental health difficulties.

In their paper on recollected experiences of first hospitalisation for acute psychosis, Zubi and Connolly ${ }^{[5]}$ have found a profound growth point for the furtherance of better attitudes, as well as better mental health practice: progressive efforts to account for the experiences of people who are mentally ill. The paper explores the qualitative properties of these experiences, which may inform how services and practices may be improved for people who are admitted for the first time for an acute psychotic episode. It is noteworthy that the subjects' experience is being taken seriously in spite of their psychiatric illness - psychiatric illness, even of a psychotic kind, does not necessarily preclude a potentially worthy contribution to the improvement of services and practices. This contribution remains modest, however, considering how much scope and need there is for developing ways in which the experiences of people suffering from psychosis and other mental illnesses may be incorporated into mental health service, practice and research.

The emerging byword of this growth point is 'co-production. ${ }^{\text {'6] }}$ Co-production brings together experts-by-training and expertsby-experience in efforts to construct jointly not only personalised treatment plans, but also diagnostic processes, as well as an approach to mental health research that extends from conceptualisation to publication. ${ }^{[7,8]}$ Considering, inter alia, the potential impairments inherent to mental illness, co-production is no doubt challenging in the mental health domain. It requires innovative and progressive work that transcends some exclusive practices hitherto, taking expertsby-experience seriously even when they are afflicted. Furthermore, it affords contributions by some people who are both experts-bytraining and experts-by-experiences. Tokenism in co-production would not do ethically, would certainly be insincere and may very well undermine the trust that is often so brittle in the mental health domain. Instead, I would like to encourage experts-by-training and experts-by-experience (and those who are qualified as both) to embark on new frontiers of joint efforts, by which mental health and attitudes towards mental illnesses and difficulties may be improved.

\section{Werdie (CW) van Staden \\ Editor: South African Journal of Psychiatry}

1. Seedat S, Emsley R. The South African Society of Psychiatrists (SASOP) Treatment Guidelines for Psychiatric Disorders 2013. S Afr J Psych 2013;19(3):128-199. [http://dx.doi.org/10.7196/ SAJP.474]

2. Moosa MYH, Jeenah FY. Provider-initiated HIV counselling and testing (PICT) in the mentally ill. S Afr J Psych 2013;19(3):60-64. [http://dx.doi.org/10.7196/SAJP.408]

3. Vijayalakshmi P, Reddy D, Math SB, Thimmaiah R. Attitudes of undergraduates towards mental illness: A comparison between nursing and business managment students in India. S Afr J Psych 2013;19(3):66-73. [http://dx.doi.org/10.7196/SAJP.398]

4. Pretorius C, Broodryk M. Misconceptions about traumatic brain injuries among South African university students. S Afr J Psych 2013;19(3):75-79. [http://dx.doi.org/10.7196/SAJP.436]

5. Zubi Y, Connolly P. Recollected experiences of first hospitalisation for acute psychosis among persons diagnosed with schizophrenia in South Africa. S Afr J Psych 2013;19(3):81-85 [http:// dx.doi.org/10.7196/SAJP.399]

6. Ostrom E. Crossing the great divide: Coproduction, synergy and development. World Development 1996;24(6):1073-1087. [http://dx.doi.org/10.1016/0305-750X(96)00023-X]

7. Flanagan O. Identity and addiction. In: Oxford Handbook of Philosophy and Psychiatry. Fulford KWM, et al. (eds). Oxford: Oxford University Press, 2013:865-888.

8. Wallcraft J, Schrank B, Amering M (eds). Handbook of Service User Involvement in Mental Health Research. London: John Wiley \& Sons Ltd, 2009.

S Afr J Psych 2013;19(3):58. DOI:10.7196/SAJP.483 